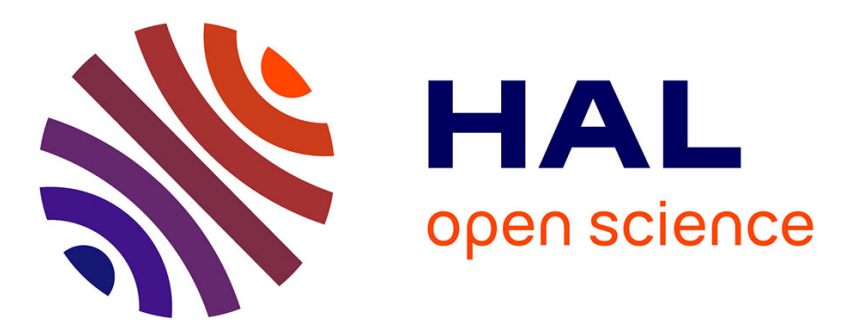

\title{
A Finite Element Calculation for the Design of Devices Made of Shape Memory Alloys
}

\author{
S. Leclercq, C. Lexcellent, J. Gelin
}

\section{To cite this version:}

S. Leclercq, C. Lexcellent, J. Gelin. A Finite Element Calculation for the Design of Devices Made of Shape Memory Alloys. Journal de Physique IV Proceedings, 1996, 06 (C1), pp.C1-225-C1-234. 10.1051/jp4:1996122 . jpa-00254154

\section{HAL Id: jpa-00254154 https://hal.science/jpa-00254154}

Submitted on 1 Jan 1996

HAL is a multi-disciplinary open access archive for the deposit and dissemination of scientific research documents, whether they are published or not. The documents may come from teaching and research institutions in France or abroad, or from public or private research centers.
L'archive ouverte pluridisciplinaire HAL, est destinée au dépôt et à la diffusion de documents scientifiques de niveau recherche, publiés ou non, émanant des établissements d'enseignement et de recherche français ou étrangers, des laboratoires publics ou privés. 


\title{
A Finite Element Calculation for the Design of Devices Made of Shape Memory Alloys
}

\author{
S. Leclercq, C. Lexcellent and J.C. Gelin
}

Laboratoire de Mécanique Appliquée R. Chaléat, URA 004 du CNRS, Faculté des Sciences et des Techniques, La Bouloie, Route de Gray, 25030 Besançon cedex, France

\begin{abstract}
In the first part of the paper a constitutive model for the pseudoelastic behavior of shape memory alloys (SMA) is presented in a finite element context. The model frame (state equation and phase transition kinetics) is rapidly described. Then the implementation of the model into a finite element code based on a fully implicit method consisting in an elastic prediction and phase transition correction is presented. Hence, the stress tensor and the tangent operator are calculated at each displacement increment. For a structural component as a thin plate subjected to bending loads, experimental data and finite element results are in a fair agreement. At last, an industrial application is treated for bronchial protheses used in medicine.
\end{abstract}

\section{INTRODUCTION}

At present time, the behavior of shape memory alloys (SMA) becomes more and more known. Indeed, many researchers are now interested in understanding how a SMA sample responds when it is submitted to a thermomechanical loading, in one or multidimensional situations. Thus, a great number of models describing the thermomechanical behavior of SMA are available in order to help the designer of structural parts including shape memory elements. Many of these models are written in one dimensional loading case [1], [2], [3]. Indeed, due to the lack of experimental data related to multidimensional loadings, it is difficult to guess the internal tensorial variable adequate to predict the multidimensional behavior. Nevertheless, recently, Raniecki and Lexcellent [4] have proposed a tensorial formulation associated to phase transition that characterized SMA. The three-dimensional model has been validated for proportional loadings by Rogueda [5] using tensile-torsion experiments on thin tubes of CuZnAl SMA. This relatively deep knowledge about SMA constitutive behavior remains, at present time, not really used by engineers and the applications of SMA are still not well developed. A reason for this is that the material models simulating the behavior of SMA are not able to predict the behavior of a complex SMA structural component. In order to help the designers of shape memory devices, it is necessary that such a material behavior can be used in finite element codes for modelling their responses to complex thermomechanical loadings. The calculations made on shape memory structural components are made either by a simple method such as strength of materials, or by implementation of the constitutive equations in a finite element code. Calculations performed by simplified methods are limited to some given geometrical structures submitted to simple mechanical loadings (bending of beams, tensile springs) [6]. Finite element calculations including SMA behavior are still in the initial state of their development. As example, Brinson and Lammering [7] used constitutive relations developed by Brinson [8] based on one-dimensional Tanaka's [2] model, but the applications are limited to one-dimensional loading cases. Rio and al. [9] have developed a three-dimensional finite element model of the elastoplastic deformation of shape memory alloys in order to perform modelling of the mechanical behavior of TiNi alloys. The formulation of this model is defined in the non linear geometrical case including large strains. The constitutive behavior is written using an elastohysteresis tensorial scheme, based on the two fundamental stress contributions of hyperelastic and pure hysteresis types. Rio and al. focussed on the simulation of different cases of plate bending of TiNi specimens under several boundary conditions. Their results give a first approach for modelling the thermomechanical behavior of 
structural components made of shape memory alloys. Raniecki and Lexcellent [4] have developed a multi-dimensional pseudoelastic model of SMA (the $\mathrm{R}_{\mathrm{L}}$ "Reference with Loop" model) based on a slightly different approach. This model will be shortly described in the first part of this paper. The second section describes the implementation of the model in a finite element code. As the $\mathrm{R}_{\mathrm{L}}$ model is similar in the form with standard elastic-plastic models, the prediction-correction method has been developed for the implementation of the $\mathrm{R}_{\mathrm{L}}$ model in the displacement based finite element method, the prediction phase consisting in evaluating a trial elastic stress, correction in taking into account irreversible strain due to phase transition. In the third section, some examples of validation of the implementation will be presented.

\section{CONSTITUTIVE BEHAVIOR OF SMA}

The $R_{L}$ model describing the pseudoelastic behavior of SMA is written in the frame of thermodynamics of irreversible processes. As the paper focusses on the mechanical aspects of this model we assume no heat exchange, i.e. constant temperature in the sample.

Our purpose here is not to present in details the possibilities of such a model, so one can refer to [4] for more details.

The model is written for three-dimensional states considering small deformation assumptions. Let be $\varepsilon, \underline{\varepsilon}^{\mathrm{e}}$, $\underline{\varepsilon}^{\text {tr }}$ the total, elastic, phase transformation strain tensors, respectively. One has

$$
\begin{gathered}
\underline{\varepsilon}=\frac{1}{2}\left(\nabla \mathbf{u}+\nabla^{\mathrm{T}} \mathbf{u}\right), \\
\underline{\varepsilon}=\underline{\varepsilon}^{\mathbf{e}}+\underline{\varepsilon}^{\mathrm{tr}} .
\end{gathered}
$$

Raniecki et al. [10] propose for proportional loadings the following transformation strain

$$
\underline{\varepsilon}^{\mathrm{tr}}=\underline{\kappa} z
$$

with $\kappa=\frac{3}{2} \gamma \frac{\operatorname{dev} \underline{\sigma}}{\bar{\sigma}}=\gamma \frac{\operatorname{dev} \underline{\varepsilon}}{\bar{\varepsilon}}$.

$\kappa$ is the traceless strain tensor associated with the formation of the martensitic phase, $\sigma$ the Cauchy stress tensor, dev $\sigma$ the deviatoric part of $\sigma, \bar{\sigma}$ (resp. $\bar{\varepsilon}$ ) the Von Mises equivalent stress (resp. strain), $\mathrm{z}$ is the martensitic volume fraction and $\gamma$ the maximum transformation strain measured on a tensile test.

The constitutive equation (3) has been improved by Rogueda [5] for some traction-torsion proportional loadings.

The constitutive equations of the material are very simple as they write

$$
\underline{\sigma}=C^{\mathrm{e}}(\underline{\varepsilon}-\underline{\kappa z}) \text {. }
$$

Here $C^{e}$ is the fourth order elasticity tensor, which is assumed to be constant.

One needs now some kinetic equations for the internal variable $z$. Let us define $\pi^{f}$ the thermodynamical force associated with $\mathrm{z}$.

$$
\pi^{\mathrm{f}}=\frac{\partial \Phi_{\mathrm{c}}}{\partial \mathrm{z}}=\gamma \frac{\bar{\sigma}}{\rho}-(1-2 \mathrm{z}) \Phi_{\mathrm{it}}(\mathrm{T})+\pi_{0}^{\mathrm{f}}(\mathrm{T}) .
$$

Here, $\Phi_{\mathrm{c}}$ is the Helmholtz free energy.

$$
\left[\begin{array}{c}
\pi_{0}^{f}(\mathrm{~T})=\Delta \mathrm{u}^{*}-\mathrm{T} \Delta \mathrm{s}^{*} \\
\Phi_{\mathrm{it}}(\mathrm{T})=\overline{\mathrm{u}_{0}}-\mathrm{T} \overline{\mathrm{s}_{0}}
\end{array}\right.
$$

As in "plasticity" the phase change corresponds to the condition $(\alpha=1$ : austenite $=>$ martensite, $\alpha=2$ : martensite $=>$ austenite).

$$
\Psi^{(\alpha)}=\text { cte }, \quad \dot{\Psi}^{(\alpha)}=0
$$


We choose

$$
\begin{gathered}
\Psi^{(1)}=\pi^{\mathrm{f}}-\mathrm{k}^{(1)}(\mathrm{z}) \quad(\mathrm{A} \Rightarrow \mathrm{M}) \\
\Psi^{(2)}=-\pi^{\mathrm{f}}+\mathrm{k}^{(2)}(\mathrm{z}) \quad(\mathrm{M} \Rightarrow \mathrm{A}) \\
\left\{\begin{array}{c}
\mathrm{k}^{(1)}(\mathrm{z})=-\left(\mathrm{A}_{1}+\mathrm{B}_{1} \mathrm{z}\right) \log (1-\mathrm{z})+\mathrm{C}_{1} \mathrm{z} \\
\mathrm{k}^{(2)}(\mathrm{z})=\left(\mathrm{A}_{2}-\mathrm{B}_{2}(1-\mathrm{z})\right) \log (\mathrm{z})-\mathrm{C}_{2}(1-\mathrm{z})
\end{array}\right. \\
\text { With }\left\{\begin{array}{cc}
\mathrm{C}_{1}=2 \Phi_{\mathrm{it}}\left(\mathrm{M}_{\mathrm{s}}^{0}\right), & \mathrm{C}_{2}=2 \Phi_{\mathrm{it}}\left(\mathrm{A}_{\mathrm{s}}^{0}\right) \\
\mathrm{a}_{1} \mathrm{~A}_{1}=\Delta \mathrm{s}^{*}-\overline{\mathrm{s}_{0}}, & \mathrm{a}_{2} \mathrm{~A}_{2}=\Delta \mathrm{s}^{*}+\overline{s_{0}} \\
\mathrm{a}_{1} \mathrm{~A}_{1}=\mathrm{a}_{2} \mathrm{~A}_{2}=2 \overline{s_{0}}
\end{array}\right.
\end{gathered}
$$

In order to write the relations of incremental kinetics, let us define

and

$$
\mathrm{d}_{\varepsilon} \pi^{\mathrm{f}}=\left(\frac{\partial \pi^{\mathrm{f}}}{\partial \underline{\varepsilon}}\right): \dot{\varepsilon}+\left(\frac{\partial \pi^{\mathrm{f}}}{\partial \mathrm{T}}\right) \dot{\mathrm{T}},
$$

$$
\mathrm{H}_{\varepsilon}^{(\alpha)}=\left(\frac{\partial \mathrm{k}^{(\alpha)}}{\partial \mathrm{z}}\right)-2 \Phi_{\mathrm{it}}+3 \mu \gamma^{2},
$$

where $\mu$ is the shear modulus of austenite and martensite (they are assumed to be equal).

The evolution equations for $\mathrm{z}$ are

$$
\dot{z}=\left(\begin{array}{ccccc}
\frac{d_{\varepsilon} \pi^{f}}{H_{\varepsilon}^{(1)}} & \text { if } & d_{\varepsilon} \pi^{f} \geq 0 & \text { and } \quad\left[\left(z>0 \text { and } \pi^{f} \geq 0\right) \text { or }\left(z=0 \text { and } \pi^{f}=0\right)\right] \\
& \frac{d_{\varepsilon} \pi^{f}}{H_{\varepsilon}^{(2)}} & \text { if } & d_{\varepsilon} \pi^{f} \leq 0 & \text { and } \quad\left[z>0 \text { and } \pi^{f} \leq 0\right] \\
& 0 & \text { otherwise }
\end{array}\right.
$$

The $\mathrm{k}^{(\alpha)}(\mathrm{z})$ functions are chosen in reference to kinetic expressions given by metallurgists (Koistinen and Marburger [11]).

All the ingredients of the model have now been given and the combination of equations (3), (4) and system (12) is sufficient to completely describe the isothermal pseudoelastic SMA behavior.

\section{FINITE ELEMENT MODELLING}

The first problem to solve is to choose one "open" code for the implementation. Indeed, we want to access to any part of the code, in order to control and check all the process. The finite element code POLYFORM 1.0 [12] combines two advantages : it is an open code and is developed in our laboratory.

\subsection{Weak form of the equilibrium equations and discretization}

The problem one has to solve is the following. Let us consider a given domain $(\Omega)$ submitted to a surface density load $\overline{\mathbf{t}}$ imposed on the part $\Gamma_{\mathbf{t}}$ of the boundary $\Gamma$, and to a volumic density load $\overrightarrow{\mathbf{f}}$. Its displacement is imposed on the part $\Gamma_{u}\left(\Gamma_{u} \cup \Gamma_{t}=\Gamma, \Gamma_{u} \cap \Gamma_{t}=\varnothing\right)$ of the boundary. One has to derive the displacement field $\mathbf{u}(\mathrm{x})$ corresponding to this loading. The general equilibrium equations and the boundary conditions are 


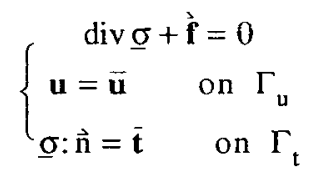

Here $\vec{n}$ is the external normal to the boundary of the domain under consideration. Let $\mathbf{u}\left(\mathrm{x}_{0}\right)$ be the displacement of a material point with position $\mathrm{x}_{0}$. The solution $\mathbf{u}\left(\mathrm{x}_{0}\right)$ is given as the displacement field that minimize the total potential energy defined as :

$$
V(\mathbf{u})=\int_{\Omega} W(\mathbf{u}) d V-\int_{\Omega} \hat{\mathbf{f}} \mathbf{u} d V-\int_{\Gamma_{1}} \overline{\mathbf{t}} \mathbf{u} d S .
$$

Let $\eta$ be the homogeneous field associated to a kinematicaly admissible field ( $\eta=0$ on $\Gamma_{\mathrm{u}}$ ). Minimizing the potential energy gives the equation

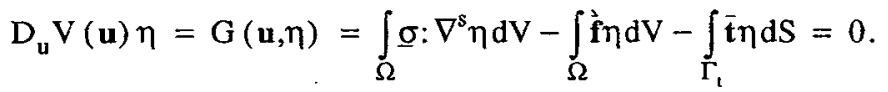

One solves equation (15) by using a Newton's method, which allows to get the displacement increment $\Delta \mathbf{u}^{\mathrm{i}}=\mathbf{u}^{\mathrm{i}+1}-\mathbf{u}^{\mathrm{i}}$ from the following equation (i is the iteration number)

$$
\mathbf{K}_{\mathrm{g}}^{\mathrm{i}} \Delta \mathbf{u}^{\mathrm{i}}=\mathbf{f}_{\text {ext }}-\mathbf{f}_{\text {int }}^{\mathrm{i}} \text {, }
$$

where $\mathbf{K}_{\mathrm{g}}^{\mathrm{i}}$ is the global stiffness matrix, $\mathbf{f}_{\text {ext }}$ the external nodal load vector and $\mathbf{f}_{\text {int }}$ the internal nodal reaction vector.

$$
\left\{\begin{array}{c}
\mathbf{K}_{\mathrm{g}}^{\mathrm{i}}=\sum_{\text {elts }} \int_{\Omega^{e}} \mathbf{B}^{\mathrm{T}}\left(\frac{\partial \underline{\sigma}^{\mathrm{i}}}{\partial \underline{\varepsilon}^{\mathrm{i}}}\right) \mathbf{B} \mathrm{dV} \\
\mathbf{f}_{\text {ext }}=\sum_{\text {elts }} \int_{\Omega^{\mathrm{e}}} \mathbf{N}^{\mathrm{T}} \mathbf{f} \mathrm{d} \mathrm{V}+\int_{\Gamma_{t}^{c}} \mathbf{N}^{\mathrm{T}} \overline{\mathbf{t} d S} \\
\mathbf{f}_{\text {int }}=\sum_{\text {elts }} \int_{\Omega^{c}} \mathbf{B}^{\mathrm{T}} \underline{\sigma}^{\mathrm{i}} \mathrm{dV}
\end{array}\right.
$$

Here, $\mathbf{B}$ is the strain interpolation matrix, $\Omega^{\mathrm{e}}$ and $\Gamma_{\mathrm{t}}^{\mathrm{e}}$ the elementary domain and load imposed boundary.

\subsection{Stress and internal variable calculation}

Now one has to calculate the stress tensor $\underline{\sigma}^{\mathrm{i}}$ at loading increment $\mathbf{n}+1$ and interation $\mathbf{i}$, and the tangent operator $C^{i}=\frac{\partial \underline{\sigma}^{i}}{\partial \underline{\varepsilon}^{i}}$. This will be done by using a classical implicit method detailled in the following part of the paper. The first step is to give an estimate of the elastic stress tensor $\sigma_{n+1}^{e}$. This estimate is given from the results of the previous convergent loading increment $n$, i.e.

$$
\underline{\sigma}_{\mathrm{n}+1}^{\mathrm{e}}=\underline{\sigma}_{\mathrm{n}}+\underline{C}^{\mathrm{e}}: \Delta \underline{\varepsilon},
$$

with $\Delta \varepsilon=\mathbf{B} \Delta \mathbf{u}$ and $\underline{\sim}^{\mathrm{e}}=\mathrm{K}(\mathrm{I} \otimes \mathrm{I})+2 \mathrm{G}\left(\mathrm{II}-\frac{1}{3}(\mathrm{I} \otimes \mathrm{I})\right)$ (I is the second order unit tensor and II the fourth order unit tensor).

The correction step is performed only if the phase transformation is verified. Otherwise, this elastic stress is the real stress at step $n+1$. Let us now examine the correction step. The stress $\sigma_{n+1}$ is the solution of the problem at the end of the increment. It reads

$$
\sigma_{n+1}=\underline{\sigma}_{n+1}^{e}-\underline{C}^{e}: \Delta \underline{\varepsilon}^{p e} \text {. }
$$


Taking the norm of the deviatoric part of equation (19), one obtains the following scalar form of equation (19):

$$
\bar{\sigma}_{n+1}=\bar{\sigma}_{n+1}^{e}-3 \mathrm{G} \gamma \Delta \mathrm{z}
$$

The use of the appropriate equation of system (12) (forward and reverse phase transition) will give one non linear equation. The classical Newton's method gives the solution $\sigma_{n+1}$. One can easily determine the stress tensor at the end of increment $n+1$ by using the following result

$$
\frac{\operatorname{dev} \underline{\sigma}_{n+1}}{\bar{\sigma}_{n+1}}=\frac{\operatorname{dev} \underline{\sigma}_{n+1}^{e}}{\bar{\sigma}_{n+1}^{e}} \text {. }
$$

One has now to calculate the tangent operator related to the phase transition. Equation (19) still holds, and its differenciation with respect to $\underline{\varepsilon}_{n+1}$ gives the tangent operator consistant with stress calculation. One obtains

$$
\frac{\partial \underline{\sigma}}{\partial \underline{\varepsilon}}=C^{\mathrm{e}}-2 \mathrm{G} \gamma\left(\left(\frac{9 \mathrm{G} \gamma}{2 \rho \mathrm{V}_{\mathrm{i}}(\mathrm{z})}-\frac{3 \Delta \mathrm{z}}{2 \bar{\varepsilon}}\right)\left(\frac{\mathrm{dev} \underline{\sigma}}{\bar{\sigma}} \otimes \frac{\operatorname{dev} \underline{\sigma}}{\bar{\sigma}}\right)+\frac{\Delta \mathrm{z}}{\bar{\varepsilon}}\left(\mathrm{II}-\frac{1}{3}(\mathrm{I} \otimes \mathrm{I})\right)\right)
$$

where $V_{i}(z)$ are related to austenite $=>$ martensite $(i=1)$ or martensite $=>$ austenite $(i=2)$ phase transition. Their expression are obtained from the consistency equations $\dot{\Psi}_{i}=0$, and they read :

$$
\begin{gathered}
\mathrm{V}_{1}=\frac{1}{\mathrm{a}_{1}}\left[\frac{\Delta \mathrm{s}^{*}+\overline{\mathrm{s}}_{0}(2 \mathrm{z}-1)}{(1-\mathrm{z})}+2 \overline{\mathrm{s}}_{0}\left(\log (1-\mathrm{z})+\mathrm{a}_{1}\left(\mathrm{~T}-\mathrm{M}_{\mathrm{s}}^{0}\right)\right)\right. \\
\left.+\frac{3 \mathrm{G} \gamma^{2}}{\rho}+\Delta \mathrm{z}\left(\frac{\Delta \mathrm{s}^{*}+\bar{s}_{0}}{(1-\mathrm{z})^{2}}+\frac{2 \bar{s}_{0}}{(1-\mathrm{z})}\right)\right] \\
\mathrm{V}_{2}=\frac{1}{\mathrm{a}_{2}}\left[\frac{\Delta \mathrm{s}^{*}-\overline{\mathrm{s}}_{0}(2 \mathrm{z}-1)}{\mathrm{z}}+2 \bar{s}_{0}\left(\log (\mathrm{z})+\mathrm{a}_{2}\left(\mathrm{~T}-\mathrm{A}_{\mathrm{s}}^{0}\right)\right)\right. \\
\left.+\frac{3 \mathrm{G} \gamma^{2}}{\rho}+\Delta \mathrm{z}\left(\frac{-\Delta \mathrm{s}^{*}+\overline{\mathrm{s}}_{0}}{\mathrm{z}^{2}}+\frac{2 \bar{s}_{0}}{\mathrm{z}}\right)\right]
\end{gathered}
$$

\section{RESULTS AND DISCUSSIONS}

In this section some results for SMA structural components (tensile tests, beam bending) obtained by using the finite element method are compared with experimental responses. After validation of the implementation, an industrial biomedical application is presented.

\subsection{Validation of the implementation}

The figures $1 \mathrm{a}$ and $1 \mathrm{~b}$ show the comparisons between finite element simulations and experiments in tensile tests performed on CuZnAl (fig.1a) and TiNi (fig.1b) alloys.

According to the construction of $\mathrm{R}_{\mathrm{L}}$ model, the finite element calculation gives the right approximation of the experimental data.

The validation of the implementation of the model at the integration point level can also be performed by making comparisons between experimental and numerical results on real structures. Thus we decide to perform some experimental bending tests on thin SMA plates. The thin plate has the following geometry : length $60 \mathrm{~mm}$, width $17 \mathrm{~mm}$, thickness $2 \mathrm{~mm}$ (figure 2). This allows us to consider that plane strain state is valid. The bending experiment performed on a CuZnAl alloy are displacement driven at the final section of the sample. Thus, we obtain a force-displacement curve at point $A$. In order to perform the numerical simulation, the thin plate is discretized by quadrangular elements and the applied load history is the same as the experimental one. Figures $3 \mathrm{a}$ and $3 \mathrm{~b}$ show the results of the experimental and numerical tests. 

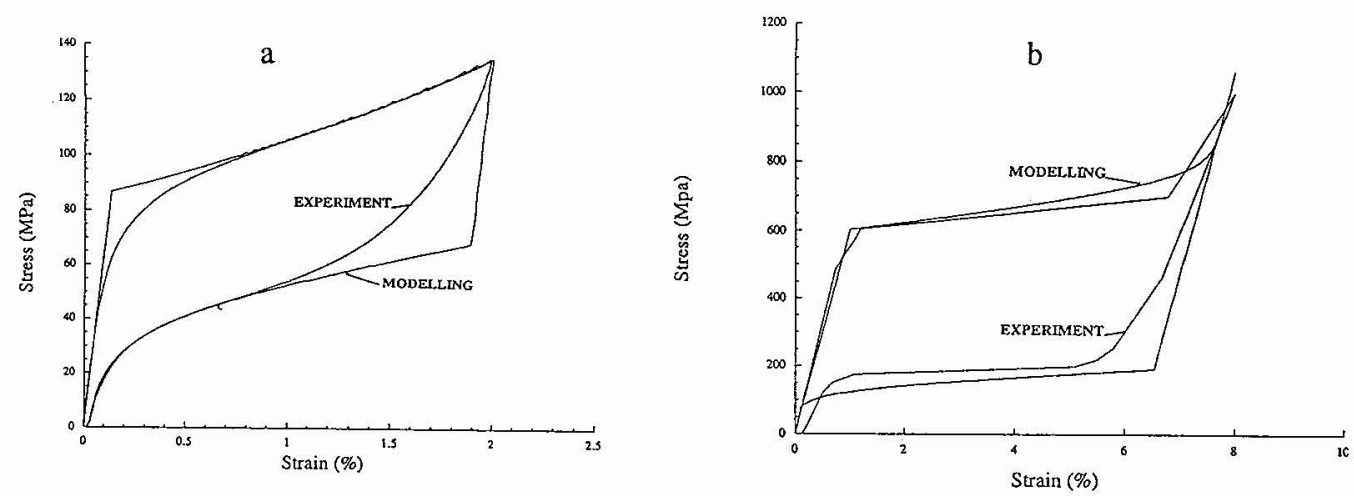

Figure 1: Loading-unloading tensile test on CuZnAl (a) and TiNi (b).

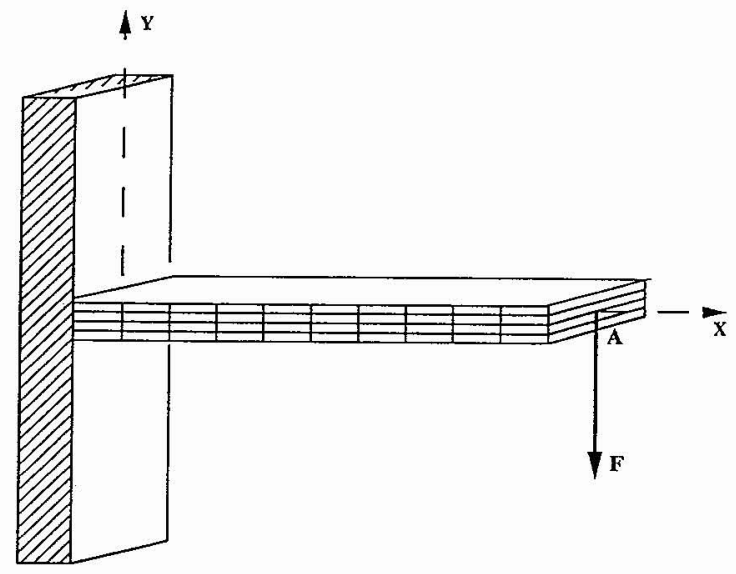

Figure 2: Schematic view of the simple bending test. 


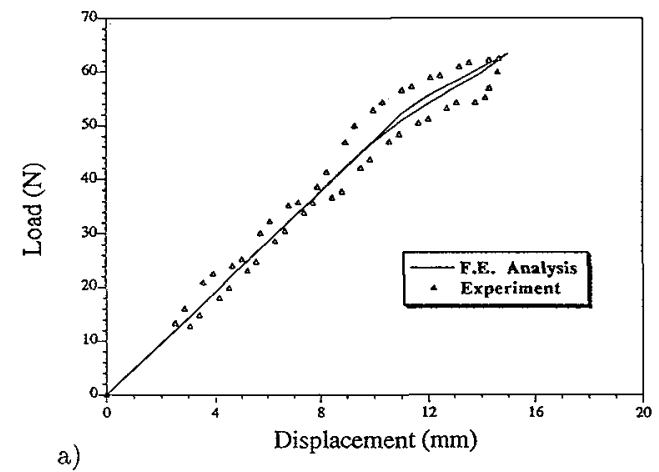

a)

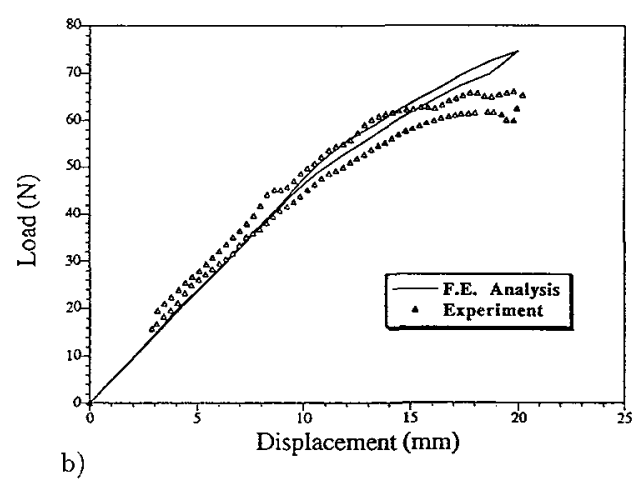

b)

Figure 3: Simple bending test : comparison between experiment and numerical data.

One can see that the numerical results are quite in agreement with experimental data. The load levels are respected. Only the width of hysteresis is smaller in numerical calculations than in experimental tests. One can give several explanations to this behavior. First, it is obvious that in the tests performed on a tensile machine, the driven displacement point moves slightly with the bending amplitude of the beam. Thus a problem of slip appears, which can be responsible for an increase of dissipation. This dissipation can be seen on the experimental curve through the area of the hysteresis loop. Second, one has to point out that the model which has been implemented is written in small strains, and that the finite element calculation is performed in the initial configuration. The case of figure $3 b$ is obviously characteristic for large strains, which is not in agreement with our hypotheses. In order to solve the problem, one should perform actualization of the current configuration at each loading increment or, better, write the model in the frame of large strains. Nevertheless, the prediction of the finite element calculation is satisfying for reasonable bending displacements.

\subsection{Application to a bronchial prothesis}

A bronchial prothesis is a small device used in medicine when the diameter of patient's bronchire is diminishing due to a cancer, for example. Figure 4 shows a schematic view of this prothesis. It is made of curved thin plates of metals embedded in two sheets of silicon. So it looks like a splitted tube.

The prothesis is used as follows : it is rolled up on itself to a very small diameter, in order to be put up in a catheter. Then, the catheter is put in the human body and the prothesis is pushed out of it at the right place. The tube returns to its initial shape (large diameter) and applies a stress on the brochire in order to prevent it to shrink.

At the beginning of the prothesis' use, the metal reinforcements were made of elastic steel. The problem was that they were not enough flexible and the rolling caused some plastic deformation. Thus, the prothesis did not apply the right stress to the bronchire and hence could cause damage in the human body. So it has been decided to perform more adaptative prothesis with thin plates made of SMA TiNi used in pseudoelastic effect conditions. The advantage can be seen in figure $1 \mathrm{~b}$. During the phase transformation, one obtains a great recoverable de formation (until 6\%) with a small stress increase. This fact allows to roll the prothesis on itself to a very thin diameter and to recover its 
previous shape after insertion in the human body. The stress applied by the prothesis can be calculated by the finite element code POLYFORM [12], in plane strain state. Figure 5 shows one half of the thin plate discretized by quadrangles for the initial shape (before being rolled) and the final shape (inside the human body). Figures 6 and 7 show the stress state $\sigma_{x x}(\mathrm{MPa})$ and $\sigma_{\mathrm{yy}}(\mathrm{MPa})$ of the thin plate being installed in the human body. The dimensions of the curved plate can thus be established in accordance with the medicine specifications.

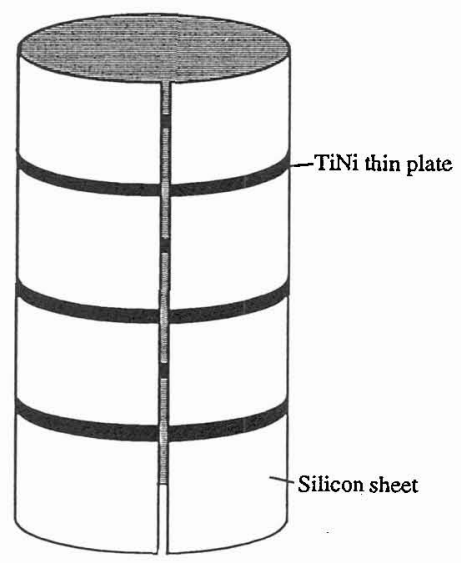

Figure 4: Schematic view of the bronchial prothesis

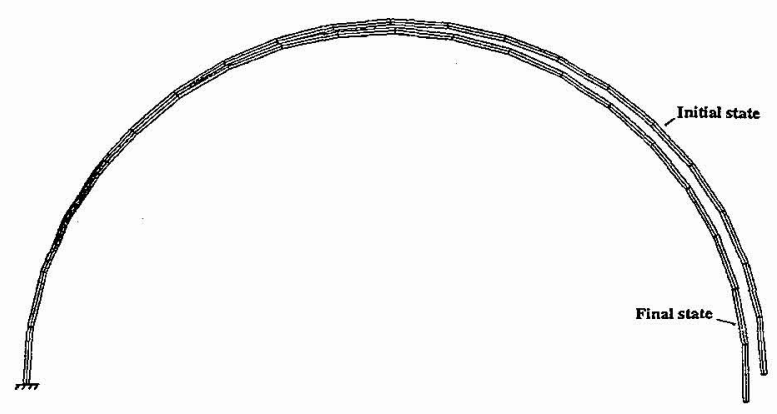

Figure 5: Discretization of one half of the thin plate 


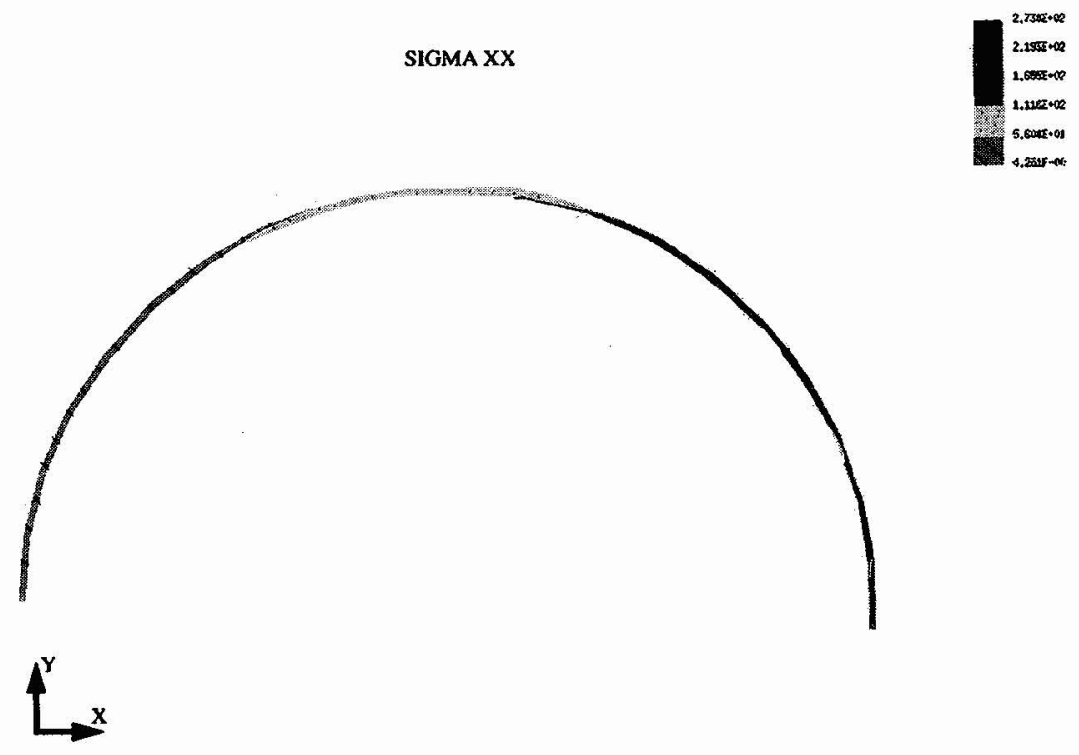

Figure 6: $\sigma_{\mathrm{xx}}$ state inside the thin plate

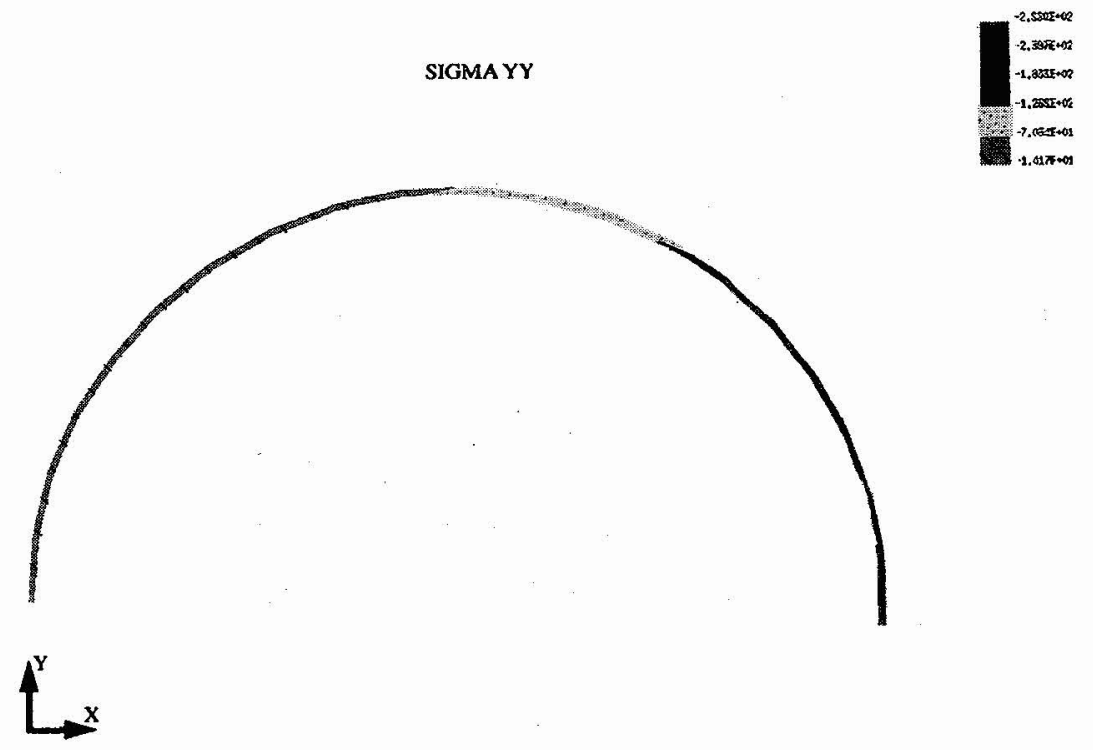

Figure 7: $\sigma_{\text {yy }}$ state inside the thin plate 


\section{CONCLUSIONS}

Based on a three-dimensional material model for shape memory alloys with internal variable, the implementation of the constitutive equations describing the pseudoelastic behavior of SMA in a finite element computer code has been presented. Taking into account that the constitutive equations for the pseudoelastic behavior are formally of the same type as the constitutive equations for standard elastoplastic materials, a prediction-correction algorithm has been formulated that allows to compute the stress and internal variable state at the end of the loading increment. From comparison with experiment results it is shown that the model permits to compute the displacement, strains and stress in complex structural situations. An original biomedical application, the bronchial prothesis, has been successfully developed. The next step now in progress is to extend the material behavior model and its finite element implementation to any thermomechanical loadings.

\section{References}

[1] Huo Y. and Müller I., Continuum Mech. Thermodyn., 5 (1993) 163-204.

[2] Tanaka K., Res. Mech., 21 , 4 (1986) 709-720.

[3] Abeyaratne R. and Knowles J.K., J. Mech. Phys. Solids, 41, 3 (1993) 541-571.

[4] Raniecki B. and Lexcellent C., Eur. J. Mech. A/Solids, 13, 1 (1994) 21-50.

[5] Rogueda C., "Modélisation thermodynamique du comportement pseudoélastique des alliages à mémoire de forme", Thèse de doctorat de l'Université de Franche Comté, n 336 (1993).

[6] Gillet Y., "Dimensionnement d'éléments simples en alliage à mémoire de forme", Thèse de l'Université de Metz (1994).

[7] Brinson L.C. and Lammering R., Int. J. Solids Structures, 30, 23 (1993) 3261-3280.

[8] Brinson L.C., "Constitutive behavior of shape memory alloys : one dimensional thermomechanical derivation with non-constant material functions and redefined martensite internal variable", Conference on Recent Advances in Adaptive and Sensory Materials and their Applications, Virginia Tech., Blaksburg (VA), 27-29 April (Technomic Publishing, 1992).

[9] Rio G., Manach P.Y. and Favier D., "Finite element simulation of shell and 3D mechanical behaviour of TiNi shape memory alloys", 30th Polish Solid Mechanics Conference, September 5-9 (1994).

[10] Raniecki B., Lexcellent C. and Tanaka K., Arch. Mech., 44, 3 (1992) 261-288.

[11] Koistinen D.P. and Marburger R.E, Acta. Met., 7 (1959) 59-60.

[12] Daniel J.L., Gelin J.C. and Paquier P., "Polyform- Logiciel 3D pour la simulation du forgeage et de l'emboutissage des matériaux", Proc. Colloque National en Calcul des Structures, M. Bernadou et al. Eds. (Hermès 1993). 